\title{
Intellectual disability-myopathy-short stature-endocrine defect syndrome
}

INSERM

\section{Source}

INSERM. (1999). Orphanet: an online rare disease and orphan drug data base. Intellectual disability-myopathy-short stature-endocrine defect syndrome. ORPHA:3068

Intellectual disability-myopathy-short stature-endocrine defect syndrome is a rare congenital myopathy syndrome characterized by nonprog ressive myopathy (manifesting with mild facial and generalized weakness, bilateral ptosis, and severe lumbar lordosis), severe intellectual disability, short stature, and sexual infantilism (due to hypogonadotropic hypogonadism). The presence of a small pituitary fossa was also noted. There have been no further descriptions in the literature since 1985. 